\title{
Study on Evaluating the Sustainability of Innovative Products
}

\author{
Lisha Geng $\mathbb{D},{ }^{1}$ Jinge Xing $\mathbb{D},{ }^{2}$ Zaojie Kong, ${ }^{3}$ Lixiao Geng, ${ }^{3}$ and Haiyan Gao $\mathbb{D}^{4}$ \\ ${ }^{1}$ School of Business Administration, Hebei University of Economics and Business, Shijiazhuang, China \\ ${ }^{2}$ Innovation Office, Shijiazhuang Vocational College for Scientific and Technical Engineering, Shijiazhuang, China \\ ${ }^{3}$ College of Economics and Management, Hebei University of Technology, Tianjin, China \\ ${ }^{4}$ School of Mathematics and Quantitative Economics, Dongbei University of Finance and Economics, Dalian, China \\ Correspondence should be addressed to Jinge Xing; babyxing09@sina.com
}

Received 4 December 2018; Revised 20 March 2019; Accepted 26 March 2019; Published 2 May 2019

Academic Editor: Dimitrios E. Manolakos

Copyright (c) 2019 Lisha Geng et al. This is an open access article distributed under the Creative Commons Attribution License, which permits unrestricted use, distribution, and reproduction in any medium, provided the original work is properly cited.

\begin{abstract}
In the process of product innovations, it is necessary to evaluate the sustainability of innovative products in order to meet the demands of sustainable development. So, the calculation process for evaluating the sustainability of innovative products is proposed in this paper. Firstly, the performances of the innovative products in social, economic, and environmental aspects are calculated based on the concepts proposed in this paper, including social matching degree, economic feasible degree, and environmental improving rate. Then, the vector-cosine method in the three-dimensional space is proposed to calculate the sustainability integrated in the three aspects, which regards innovative products as the vectors. Both the size and direction of the vectors are considered to calculate the sustainability. Finally, a case study of the cloud rail made by BYD Company in China is provided to illustrate the validity of the proposed calculation process.
\end{abstract}

\section{Introduction}

With the rapid development of society and economy, people's life is undergoing a great change. In order to keep pace with the development of people's modern lifestyle and behavior, enterprises continuously develop innovative products. However, they unavoidably accelerate the consumption and wastes of natural resources at the same time. Environmental pollution, resource depletion, ecological disaster, and other global environmental problems have confined the sustainable development of human, even threatened the security of human. Customers require more sustainable products, and governments also announced policies to diminish environmental impacts during the whole life cycle of products [1]. Enterprises have tried a number of approaches for designing environmentally friendly products [2]. Traditional design that neglects the impact on the environment is not beneficial to human survival and development, so product design has undergone from traditional design, green design, and ecodesign to sustainable design in recent years. Sustainable design is originated from the concept of sustainable production that was put forward at the United Nations Conference on Environment and Development (UNCED) in 1992 [3]. It aims to design sustainable products by reducing costs and environmental impacts during products' whole life cycle. Three elements must be taken into consideration for achieving sustainability based on the concept of triple bottom line proposed by Elkington in 1997, as shown in Figure $1[4,5]$. Sustainability also represents the harmony of the exploitation of resources, investment plans, technological development, and institutional changes [6]. With the deepening of the concept of sustainable development, enterprises have realized the importance of sustainability in products [7], and an unprecedented number of enterprises try to provide sustainable products that are good for both the planet and humankind [8].

So evaluating the sustainability of innovative products is of vital importance for enterprises in the process of innovation. This paper aims to provide quantitative methods to evaluate innovative products' sustainability. Since sustainability is an integrated concept in society, economy, and 


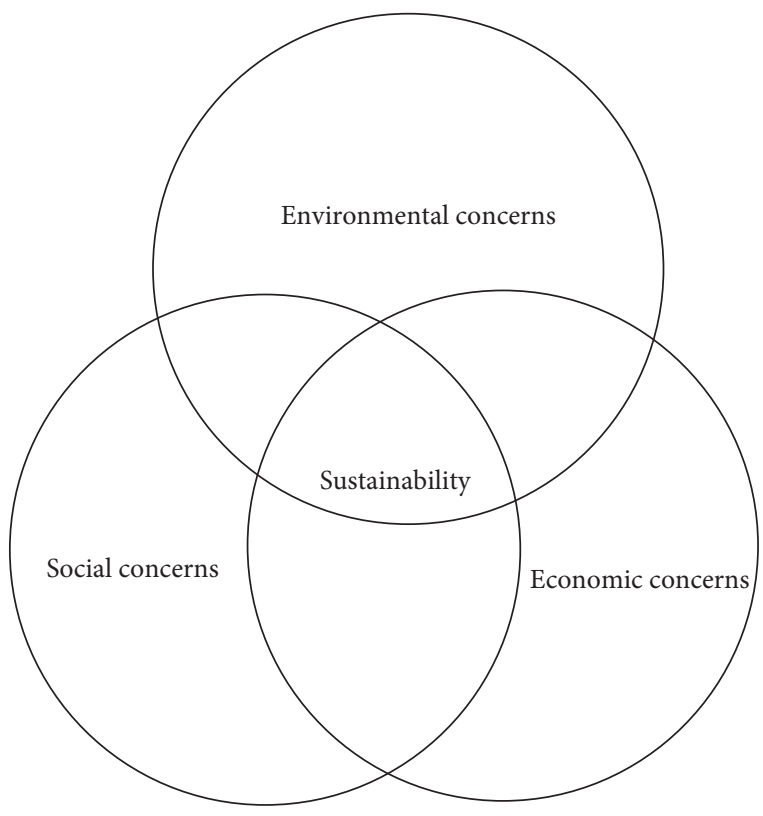

Figure 1: Triple bottom line of sustainability [4].

the environment, the evaluation of sustainability should firstly include the evaluation of innovative products in social, economic, and environmental aspects, respectively. Then, an evaluation integrating the three aspects should be done to get the final sustainability. In this paper, we attempt to address the following research questions:

(1) How to quantitatively evaluate the social, economic, and environmental performance respectively for innovative products?

(2) How to quantitatively evaluate the sustainability for innovative products by integrating social, economic, and environmental performances?

\section{Literature Review}

Products' sustainability has received the attention of many scholars. Products need to be holistically improved, and the products with ecological or social improvements have not achieved the final destination of sustainability [2]. The tools for achieving sustainability for products have been divided into two kinds: the tools for partial sustainability and the tools for total sustainability. By comparison, tools for partial sustainability are more mature and useful in the early design stage [9]. Besides, information, environmental concern, and ethical production influence consumers' attitudes towards products' sustainability [10].

Many approaches have been proposed by scholars for designing sustainable products. LCA (life cycle assessment), which has been applied as a dispensable tool for designing sustainable product, can assess products' environmental impacts during the whole life cycle [11]. In addition, many methods have been applied at the end of life of products, such as design for disassembly [12], design for reuse [13], design for EOL [14], and design for remanufacturing [15]. These methods are applied by enterprises to maximize the value of product components and prolong the life of products. However, they cannot evaluate products' performances in social and economic aspects in an integrated way.

Generally speaking, the sustainability of products can be evaluated from two perspectives: the perspective of life cycle and the perspective of the triple bottom line. Life cycle emphasizes product's total impact "from cradle to grave", while the triple bottom line stresses the integrated impact in social, economic, and environmental aspects [16]. The methods which combine the two perspectives are proved to be more effective. For example, life cycle sustainability assessment (LCSA), which combines life cycle assessment (LCA), life cycle costing (LCC), and social life cycle assessment (SLCA) [17]. In order to evaluate the sustainability of renewable energy systems, life cycle analysis (LCA) and multicriteria decision making (MCDM) are also integrated [18]. Existing literature has studied how to achieve and evaluate the sustainability of products. With the sustainable development idea striking root in people's hearts gradually, evaluating the sustainability plays an important role in the success development of innovative products. However, existing research has the following research gaps:

(1) The evaluation of product's sustainability is a quantitative calculation process. The evaluation data are obtained from experts, so the data have the characteristics of subjectivity and uncertainty. How to deal with the subjectivity and uncertainty in the evaluation data has not been dealt with.

(2) Social, economic, and environmental performances of products are mutually restrictive, so the sustainability evaluation of products is not simply the addition of the performances in three aspects. So how to calculate the sustainability by integrating the three aspects has not be solved.

In order to solve the above two problems, this paper proposes a calculation process with quantitative methods for evaluating the sustainability of innovative products.

\section{Research Framework}

Nowadays, innovative products with higher sustainability have more advantages in the fierce market competition. The sustainability evaluation process helps decision makers to estimate whether the products innovated are sustainable or not.

Since the sustainability of innovative products includes social, economic, and environmental aspects, the concepts including social matching degree, economic feasible degree, and environmental improving rate are proposed to evaluate the performance in every aspect, respectively. The evaluation data obtained from experts are uncertain and subjective to a certain extent. In order to deal with the uncertainties of the data provided by experts, the fuzzy theory is applied to form a fuzzy evaluation matrix to calculate social matching degree. Entropy weight method, an objective weighting method, is applied to deal with the subjectivity of the data 
provided by experts to calculate economic feasible degree. Considering the cost and complexity of LCA software, simplified LCA is used to calculate the environmental improving rate, which is suitable for small- and medium-sized enterprises in China. In order to integrate social matching degree, economic feasible degree, and environmental improving rate for innovative products, this paper proposes a vector-cosine method in the three-dimensional space. The research framework is shown in Figure 2. With the quantitative methods applied in the paper, the uncertainty and subjectivity of data are dealt with. In addition, the integration of data in the three aspects of sustainability is also achieved.

3.1. Calculating the Social Matching Degree. In order to achieve the sustainability in social aspect, innovative products should meet social requirements, which include the requirements of both the society as a whole and the individuals in the society. For example, because of the continuous fog haze weather in mid-eastern China, low pollution of public transport has become an urgent requirement for the whole society. At the same time, the fog haze has threatened the health of people, so low pollution of public transportation has also become the requirements of the individuals in the society.

After acquiring social requirements for a product, there is a need to evaluate the social matching degree of the innovated product. In this part, an evaluation matrix including five grades is firstly built to evaluate how the innovative product matches social requirements. Then, five indicators representing the five grades constitute a five-dimensional space. The distance formula in the five-dimensional space is applied to calculate the social matching degree. The specific steps are as follows.

3.1.1. Building a Fuzzy Matching Degree Matrix. After obtaining social requirements through market survey, the basic importance weights of social requirements are calculated by the importance and probability comprehensive coefficient method and adjusted by KANO model to gain the final importance weights from the perspectives of both customers and designing experts [19]. An evaluation set represented by $V$ is built to assess the matching degree between the innovative product and social requirements:

$$
\begin{aligned}
V= & \left\{V_{1}, V_{2}, V_{3}, V_{4}, V_{5}\right\} \\
= & \{\text { completely match, relatively match, match, } \\
& \text { rarely match, not match }\}
\end{aligned}
$$

In the following formulas, $C R$ and $W$ represent social requirements and their weights, respectively. $R$ is the fuzzy evaluation matrix, which evaluates how the innovative product matches the social requirements. An evaluation table is formed based on social requirements, their weights, and the evaluation matrix, as shown in Table 1, where both $W$ and $R$ are the standardized results.

$$
\begin{aligned}
\mathrm{CR} & =\left\{\mathrm{CR}_{1}, \mathrm{CR}_{2}, \ldots, \mathrm{CR}_{n}\right\}, \\
W & =\left\{W_{1}, W_{2}, \ldots, W_{n}\right\}, \\
R & =\left[\begin{array}{ccccc}
r_{11} & r_{12} & r_{13} & r_{14} & r_{15} \\
r_{21} & r_{22} & r_{23} & r_{24} & r_{25} \\
\vdots & \vdots & \vdots & \vdots & \vdots \\
r_{n 1} & r_{n 2} & r_{n 3} & r_{n 4} & r_{n 5}
\end{array}\right], \\
\sum_{j=1}^{n} w_{j} & =1, \\
\sum_{i=1}^{n} r_{i j} & =1, \quad j=1,2, \ldots, 5 .
\end{aligned}
$$

According to the algorithm of matrix, the comprehensive evaluation vector $B$ is calculated by the following formula:

$$
B=W * R=\left\{B_{1}, B_{2}, B_{3}, B_{4}, B_{5}\right\} \text {. }
$$

3.1.2. Calculating the Social Matching Degree Based on the Distance Formula. $D_{1}$ and $D_{2}$ are taken as the standard points in the five-dimensional space. $D_{1}$ represents the ideal situation where the innovative product completely matches social requirements. $D_{2}$ represents the negative ideal situation where the innovative product does not match social requirements at all. $\left|B D_{1}\right|$ represents the distance between $B$ and $D_{1}$, and $\left|B D_{2}\right|$ represents the distance between $B$ and $D_{2}$. The social matching degree of the innovative product represented by $\lambda_{1}$ is calculated by formulas (5) and (6):

$$
\begin{aligned}
D_{1} & =(1,0,0,0,0), \\
D_{2} & =(0,0,0,0,1), \\
\left|B D_{1}\right| & =\left[\left(B_{1}-1\right)^{2}+\left(B_{2}-0\right)^{2}+\left(B_{3}-0\right)^{2}+\left(B_{4}-0\right)^{2}+\left(B_{5}-0\right)^{2}\right]^{1 / 2}, \\
\left|B D_{2}\right| & =\left[\left(B_{1}-0\right)^{2}+\left(B_{2}-0\right)^{2}+\left(B_{3}-0\right)^{2}+\left(B_{4}-0\right)^{2}+\left(B_{5}-1\right)^{2}\right]^{1 / 2}, \\
\lambda_{1} & =\frac{\left|B D_{2}\right|}{\left|B D_{1}\right|+\left|B D_{2}\right|} .
\end{aligned}
$$

3.2. Calculating the Economic Feasible Degree. The evaluation data of economic feasible degree for innovative products are obtained from experts in the R\&D department. Because the data are the result of artificial input, they have subjectivity to some extent. Influenced by the number of experts, the data provided by experts are usually poor. So, the entropy weight method, which provides a way to get the weights by less data without subjective effect, is applied to calculate the weights of economic indicators [20]. TOPSIS (Technique for Order of Preference by Similarity to Ideal Solution), proposed by Li et al., is a multiple criteria decision making method [21]. According to TOPSIS, there are two states of economic feasible degree for innovative products: 


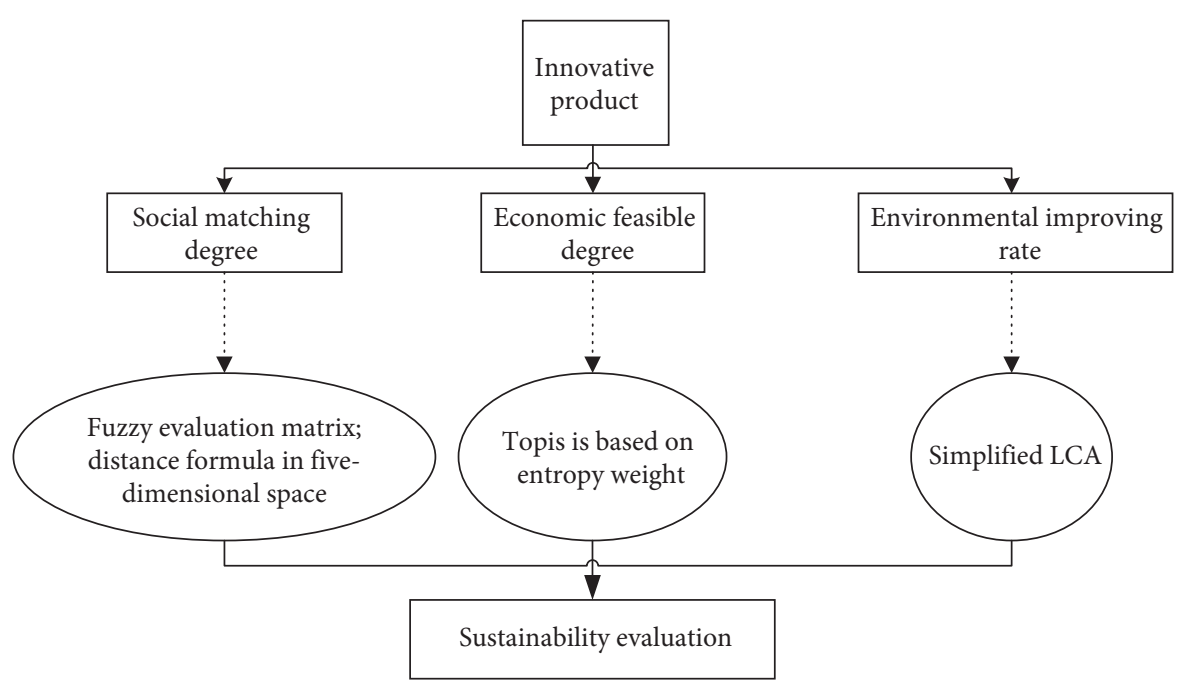

FIgURE 2: The framework for evaluating the sustainability of innovative products.

TABle 1: The evaluation table of social matching degree.

\begin{tabular}{lcccccc}
\hline Social & Weights of & \multicolumn{5}{c}{ Evaluation matrix } \\
requirements & importance & $V_{1}$ & $V_{2}$ & $V_{3}$ & $V_{4}$ & $V_{5}$ \\
\hline $\mathrm{CR}_{1}$ & $W_{1}$ & $r_{11}$ & $r_{12}$ & $r_{13}$ & $r_{14}$ & $r_{15}$ \\
$\mathrm{CR}_{2}$ & $W_{2}$ & $r_{21}$ & $r_{22}$ & $r_{23}$ & $r_{24}$ & $r_{25}$ \\
$\vdots$ & $\vdots$ & $\vdots$ & $\vdots$ & $\vdots$ & $\vdots$ & $\vdots$ \\
$\mathrm{CR}_{n}$ & $W_{n}$ & $r_{n 1}$ & $r_{n 2}$ & $r_{n 3}$ & $r_{n 4}$ & $r_{n 5}$ \\
\hline
\end{tabular}

the ideal state and the negative ideal state. Based on the formula of TOPSIS, the economic feasible degrees are evaluated by calculating the distances of innovative products from the ideal state and the negative ideal state, respectively. The calculation steps are as follows.

3.2.1. Calculating with the Entropy Weight Method. The entropy weight method is an objective way to identify the weights of indicators according to the information provided by indicators. The smaller the entropy of the indicator, the bigger is its variant degree. The indicators with bigger variant degree provide more information, so they have bigger weights. Experts are invited to evaluate the feasible degree of economic indicators for innovative products. The number of experts and indicators are represented by $m$ and $n$, respectively. So, an evaluation matrix, represented by $X$, is formed. Standardize the matrix if needed by formula (7). The entropy, represented by $E_{j}$, is calculated by formula (8). When $P_{i j}$ equals $0, p_{i j} \ln p_{i j}$ equals 0 . In formula (9), $w_{j}$ represents the entropy weight of the indicator. The bigger its weight is, the more important it is:

$$
\begin{aligned}
X & =\left(x_{i j}\right)_{m \times n}, \quad i=1,2, \ldots, m, j=1,2, \ldots, n, \\
P_{i j} & =\frac{x_{i j}}{\sum_{i=1}^{m} x_{i j}}, \\
E_{j} & =-\frac{\sum_{i=1}^{m} p_{i j} \ln p_{i j}}{\ln m},
\end{aligned}
$$

$$
\begin{aligned}
w_{j} & =\frac{1-E_{j}}{n-\sum_{j=1}^{n} E_{j}}, \\
\sum_{j=1}^{n} w_{j} & =1
\end{aligned}
$$

3.2.2. Calculating with TOPSIS. TOPSIS is applied to evaluate the feasible degree of economic indicators for innovative products by calculating the distances from the ideal and negative ideal states of innovative products. $A^{*}$ and $A^{-}$represent the ideal state and the negative state of innovative products, respectively. The ideal state means the feasible degrees of all economic indicators are the highest; the negative ideal state means the feasible degrees of all economic indicators are the lowest. $D_{j}^{*}$ and $D_{j}^{-}$, which represent the Euclidean distances of indicators from the ideal state and the negative ideal state, respectively, are calculated by formula (10). Then, the Euclidean distances are calculated by formula (11):

$$
\begin{aligned}
A^{*} & =\left\{r_{1}^{*} r_{2}^{*} \cdots r_{n}^{*}\right\}=\{1,1, \ldots, 1\}, \\
A^{-} & =\left\{r_{1}^{-} r_{2}^{-} \cdots r_{n}^{-}\right\}=\{0,0, \ldots, 0\}, \\
D_{j}^{*} & =\sqrt{\sum_{i=1}^{m}\left(r_{i j}-r_{j}^{*}\right)^{2}, \quad j=1,2, \ldots, n,} \\
D_{j}^{-} & =\sqrt{\sum_{i=1}^{m}\left(r_{i j}-r_{j}^{-}\right)^{2}}, \quad j=1,2, \ldots, n, \\
K_{j}^{*} & =w_{j} D_{j}^{*}, \\
K_{j}^{-} & =W_{j} D_{j}^{-}, \\
D_{j}^{*}, D_{j}^{-} & \in[0,1] .
\end{aligned}
$$

The larger the value of $K_{j}^{-}$, the shorter the distance between the indicators and the ideal state; the larger the value of $K_{j}^{*}$, the longer the distance between the indicators 
and the ideal state. So, the economic feasible degree, represented by $\lambda_{2}$, is calculated by the following formula:

$$
\lambda_{2}=\frac{\sum_{j=1}^{n} K_{j}^{*}}{\sum_{j=1}^{n}\left(K_{j}^{*}+K_{j}^{-}\right)} .
$$

3.3. Calculating the Environmental Improving Rate. Life cycle assessment (LCA) is a method applied to evaluate products' impact on the environment during the whole life cycle $[22,23]$. Generally speaking, LCA includes four steps: goal and scope, life cycle inventory, life cycle impact assessment, and interpretation [22].

Although LCA can provide a detailed assessment for products, it is time-consuming and requires a lot of products' detailed data. LCA software, such as Gabi and Simapro, are too expensive for the small- and medium-sized enterprises in China. In addition, it is needed to make a comparison between existing products and innovative products in environmental impacts during the innovation process. Innovative products will take an advantage if they have less environmental impact. The AT\&T abridged life cycle assessment method [24], proposed by Graedel et al., is applied in this paper to forecast the environmental improving rate of innovative products. The main steps of the method are as follows: at first, a $5 \times 5$ assessment matrix is built, as shown in Table 2. It includes the stages of preproduction, production, transportation, usage, and disposal in product's life cycle. Environmental impact of material choice, energy use, solid residues, liquid residues, and gaseous residues is also included in the table. Then, every blank of the table is filled with two integers from 0 to 4 , where 0 represents the highest environmental impact and 4 represents the lowest environmental impact. The first integer in every blank represents the environmental impacts of innovative product; the second one represents the environmental impacts of existing product. So, a comparison evaluation is made by an environmental expert. $S_{r}$, which represents the overall environmentally responsible product rating, is calculated as the sum of all the 25 blanks. $S_{1}$ represents the sum of existing product, $S_{2}$ represents the sum of the innovative product, and $\lambda_{3}$ represents the environmental improving rate. The environmental improving rate is calculated by formula (13). When $S$ equals 100 , the environmental improving rate is 1 , which means the innovative product has the highest environmental improving rate:

$$
\begin{aligned}
& S_{i}=100, \\
& S_{r}=\sum_{i} \sum_{j} M_{i j}, \quad r=1,2, i=1,2, \ldots, 5, j=1,2, \ldots, 5, \\
& \lambda_{3}=\frac{S_{2}-S_{1}}{S_{i}-S_{1}}, \quad \lambda_{3} \in[0,1] .
\end{aligned}
$$

3.4. Calculating the Sustainability Using the Vector-Cosine Method. According to the triple bottom line of sustainability, the sustainability includes social, economic, and
TABLE 2: $5 \times 5$ assessment matrix [24].

\begin{tabular}{lccccc}
\hline \multirow{2}{*}{ Life cycle } & \multicolumn{5}{c}{ Environmental impacts } \\
& Materials & $\begin{array}{c}\text { Energy } \\
\text { use }\end{array}$ & $\begin{array}{c}\text { Solid } \\
\text { residues }\end{array}$ & $\begin{array}{c}\text { Liquid } \\
\text { residues }\end{array}$ & $\begin{array}{c}\text { Gaseous } \\
\text { residues }\end{array}$ \\
\hline Preproduction & 1,1 & 1,2 & 1,3 & 1,4 & 1,5 \\
Production & 2,1 & 2,2 & 2,3 & 2,4 & 2,5 \\
Transportation & 3,1 & 3,2 & 3,3 & 3,4 & 3,5 \\
Usage & 4,1 & 4,2 & 4,3 & 4,4 & 4,5 \\
Disposal & 5,1 & 5,2 & 5,3 & 5,4 & 5,5 \\
\hline
\end{tabular}

environmental aspects. However, the evaluation of sustainability is not the simple addition of the three aspects because the three aspects are mutually restrictive. For example, pursuing economic interests blindly will inevitably lead to an increase in environmental impacts. Similarly, pursuing environmental improvement purely will inevitably result in the loss of economic benefits. So there is a balanced state for the three aspects. In this part, the sustainability of the innovative product is calculated using the vector-cosine method. The values representing the performance in every aspect form a three-dimensional space, as shown in Figure 3. It is found that $O T^{*}$ is the ideal direction, which represents the three aspects in a balanced state. The angles between the ideal direction and each axis are $45^{\circ} . X, Y$, and $Z$ represent the values of $\lambda_{1}, \lambda_{2}$, and $\lambda_{3}$, respectively. With the vectorcosine method, both the size and its deviation angle from the ideal direction of the vector are taken into account.

In Figure 3, $\mathrm{OT}^{*}$ is formed by the projections of all the vectors on the ideal direction. $\theta$ represents the deviating angle from the ideal direction. $O$ and $T^{*}$ represent the negative ideal state and the ideal state, respectively. $\rho$ is the projection of the vector, which not only considers the size but also the direction of the vector. So, the sustainability of the innovative product, represented by $\rho$, is calculated by the formulas (14) and (17).

There are two vectors represented by $T_{r}$ and $T_{s}$, respectively. $\theta_{r}$ and $\theta_{s}$ represent their angles deviated from the ideal direction, respectively. The distance between $T_{r}$ and $T_{s}$, represented by $d_{r s}$, is calculated by formula (18). $T^{*}$ represents the vector of the ideal innovative product, and $T^{-}$ represents the vector of the negative ideal innovative product. The distance between the ideal innovative product and the negative ideal product, represented by $d_{*-}$, is calculated by formula (19):

$$
\begin{aligned}
T & =\left(\lambda_{1}, \lambda_{2}, \lambda_{3}\right), \\
O & =(0,0,0), \\
T^{*} & =(1,1,1), \\
O T & =\sqrt{\left(\lambda_{1}-0\right)^{2}+\left(\lambda_{2}-0\right)^{2}+\left(\lambda_{3}-0\right)^{2}} \\
& =\sqrt{\lambda_{1}^{2}+\lambda_{2}^{2}+\lambda_{3}^{2}}, \\
\theta & =\frac{\arccos \left[\left(O T^{*}\right)^{2}+(O T)^{2}-\left(T T^{*}\right)^{2}\right]}{2 \times O T^{*} \times O T},
\end{aligned}
$$




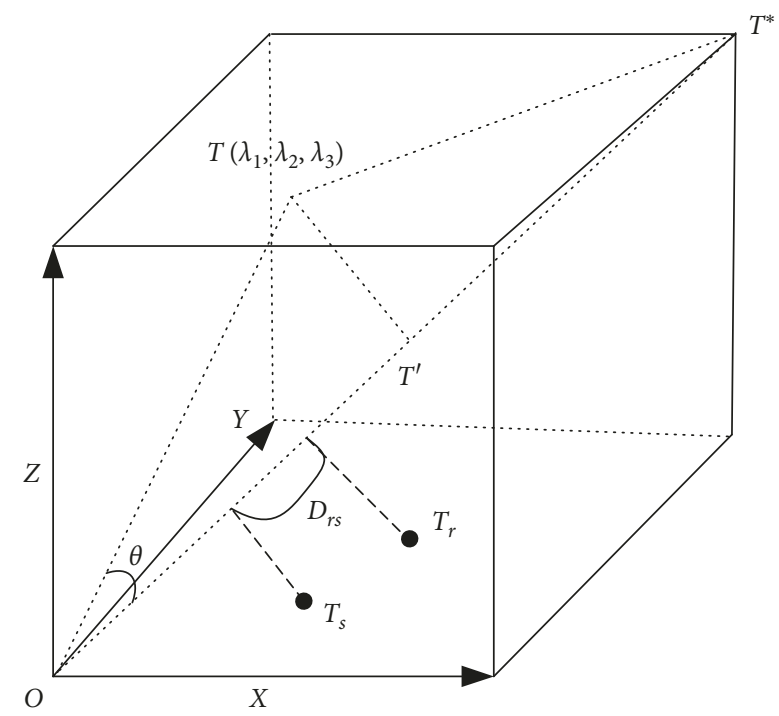

FIgURE 3: Vector-cosine method in three-dimensional space.

$$
\begin{aligned}
T T^{*} & =\sqrt{\left(1-\lambda_{1}^{2}\right)+\left(1-\lambda_{2}^{2}\right)+\left(1-\lambda_{3}^{2}\right)}, \\
\rho & =O T^{\prime}=O T \times \cos , \\
d_{r s} & =\left|O T_{r} \times \cos \theta_{r}-O T_{s} \times \cos \theta_{s}\right|, \\
T^{*} & =(1,1,1), \quad \theta=0, \rho^{*}=\sqrt{3}, \\
T^{-} & =(0,0,0), \quad \rho^{-}=0, \\
0 & \leq \rho \leq \sqrt{3}, \\
d_{*-} & =\rho^{*}-\rho^{-}=\sqrt{3} .
\end{aligned}
$$

It is calculated that $\rho$ is between 0 and $\sqrt{3}$, which represent the lowest and the highest sustainability of the innovative product. Based on the values of $\rho$, Table 3 gives a grade standard of the sustainability.

\section{Case Study}

BYD is a high-tech private enterprise of IT, automobile, and new energy in China. The iron battery energy storage system and permanent magnet rim direct driving motor are the core technologies of BYD. They help BYD to take an advantage in the market by manufacturing the new energy vehicles. In 2016, BYD released its innovative public transport vehicle: cloud rail [25], as shown in Figure 4. Cloud rail is developed by BYD's self-developed technologies and other leading technologies including lightweight body, single axle bogie, energy feedback communication system, and auxiliary automatic driving, as shown in Figure 5. Cloud rail is actually a straddle-type monorail train, which uses the rubber wheel and concrete to lose weight and avoid noises. The track is a vertical concrete beam, and cloud rail "rides" on it.

4.1. Evaluation Process. Cloud rail has the advantages of strong ability to climb, small turning diameter (45 meters), low noise,
TABLE 3: Grade standard of the sustainability.

\begin{tabular}{lccc}
\hline Grade & Low & Medium & High \\
\hline$\rho$ & $0-0.58$ & $0.58-1.15$ & $1.16-\sqrt{3}$ \\
\hline
\end{tabular}

and low energy consumption. In order to evaluate the sustainability of cloud rail, the following steps are implemented.

4.1.1. Step 1: Calculating the Social Matching Degree. A survey of social requirements for public traffic is done in Beijing, Tian Jin, and Shijiazhuang in 2017. After collecting the requirements data and calculating the importance weights with the method of determining the importance weights of customer requirements [19], the first ten social requirements are selected:

$$
\begin{aligned}
\mathrm{CR}= & \left\{\mathrm{CR}_{1}, \mathrm{CR}_{2}, \ldots, \mathrm{CR}_{10}\right\}, \\
= & \{\text { safe, fast, less traffic jam, low investment cost, } \\
& \text { short construction period, low pollution, } \\
& \text { low running noise, easy maintenance, } \\
& \text { saving land resources, low recovery cost }\}, \\
W= & \left\{w_{1}, w_{2}, \ldots, w_{10}\right\}, \\
= & \{0.17,0.16,0.15,0.12,0.10,0.09,0.08,0.05,0.05,0.03\} .
\end{aligned}
$$

Ten experienced engineers and socialists are invited to assess the matching degree of cloud rail with the figures from 0 to 1 , where 0 represents the lowest matching degree and 1 represents the highest matching degree. The evaluation values are standardized, and the results are shown in Table 4. Vector $B$ is calculated according to formula (4), and $\lambda_{1}$ is calculated according to formulas (5) and (6). The calculating results are as follows:

$$
\begin{aligned}
\mathrm{CR} & =\left\{\mathrm{CR}_{1}, \mathrm{CR}_{2}, \ldots, \mathrm{CR}_{10}\right\}, \\
W & =\left\{w_{1}, w_{2}, \ldots, w_{10}\right\}, \\
& = \begin{cases}* \\
B\end{cases} \\
& *\left[\begin{array}{ccccc}
0.9 & 0.1 & 0 & 0 & 0 \\
1 & 0 & 0 & 0 & 0 \\
1 & 0 & 0 & 0 & 0 \\
0.8 & 0.1 & 0.1 & 0 & 0 \\
0.7 & 0.2 & 0.1 & 0 & 0 \\
0.9 & 0.1 & 0 & 0 & 0 \\
0.9 & 0.1 & 0 & 0 & 0 \\
0.7 & 0.1 & 0.1 & 0 & 0 \\
0.9 & 0.1 & 0 & 0 & 0 \\
0.6 & 0.2 & 0.2 & 0 & 0
\end{array}\right] \\
= & (0.88,0.08,0.04,0,0), \\
\lambda_{1}= & \frac{\left|B D_{2}\right|}{\left|B D_{1}\right|+\left|B D_{2}\right|}=\frac{1.34+0.15}{1.34}=0.9 .
\end{aligned}
$$




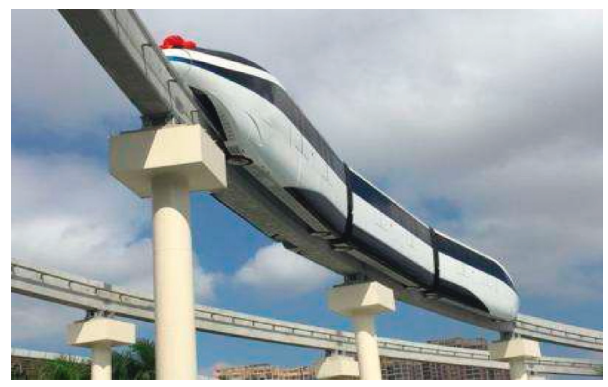

Figure 4: The cloud rail [25].

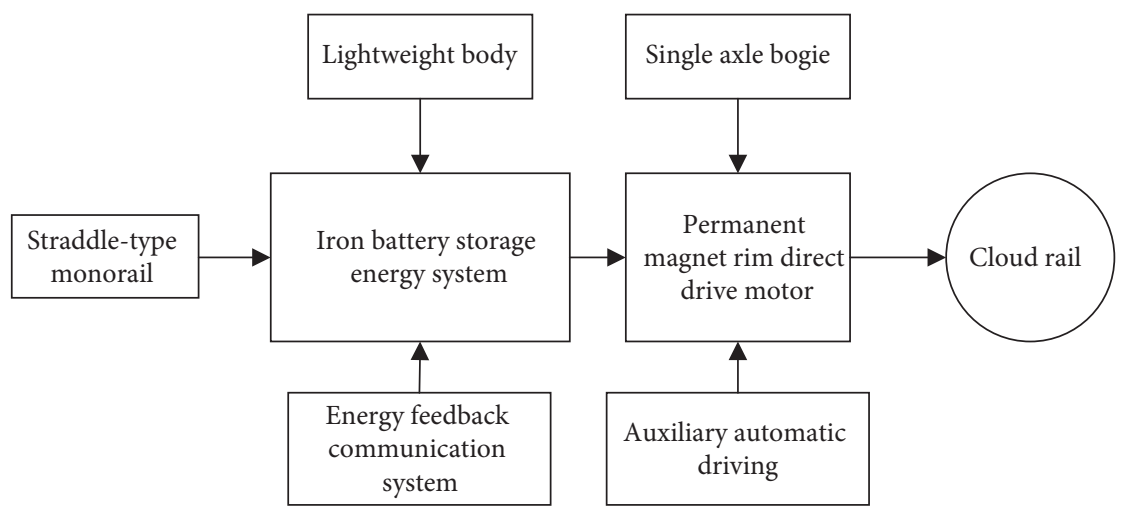

FIGURE 5: The core technologies for developing cloud rail.

TABLe 4: The evaluation for social matching degree.

\begin{tabular}{lcccccc}
\hline \multirow{2}{*}{ Requirements } & \multirow{2}{*}{ Weights of importance } & \multicolumn{7}{c}{ Assessment results } \\
& & $V_{1}$ & $V_{2}$ & $V_{3}$ & $V_{4}$ & $V_{5}$ \\
\hline $\mathrm{CR}_{1}$ & 0.17 & 0.9 & 0.1 & 0 & 0 & 0 \\
$\mathrm{CR}_{2}$ & 0.16 & 1 & 0 & 0 & 0 & 0 \\
$\mathrm{CR}_{3}$ & 0.15 & 1 & 0 & 0 & 0 & 0 \\
$\mathrm{CR}_{4}$ & 0.12 & 0.8 & 0.1 & 0.1 & 0 & 0 \\
$\mathrm{CR}_{5}$ & 0.10 & 0.7 & 0.2 & 0.1 & 0 & 0 \\
$\mathrm{CR}_{6}$ & 0.09 & 0.9 & 0.1 & 0 & 0 & 0 \\
$\mathrm{CR}_{7}$ & 0.08 & 0.9 & 0.1 & 0 & 0 & 0 \\
$\mathrm{CR}_{8}$ & 0.05 & 0.7 & 0.1 & 0.2 & 0 & 0 \\
$\mathrm{CR}_{9}$ & 0.05 & 0.9 & 0.1 & 0 & 0 & 0 \\
$\mathrm{CR}_{10}$ & 0.03 & 0.6 & 0.2 & 0.2 & 0 & 0 \\
\hline
\end{tabular}

4.1.2. Step 2: Calculating the Economic Feasible Degree. Five experts are invited to evaluate the economic feasible degree of cloud rail with six indicators. $E$ represents the set of economic feasible indicators. 1 represents the highest feasible degree, and 0 represents the lowest feasible degree. Choose the number between 0 and 1 to evaluate the economic feasible degree. The results are shown in Table 5. Because the values are all from 0 to 1 , Table 5 need not be standardized:

$$
\begin{aligned}
E= & \left(E_{1}, E_{2}, E_{3}, E_{4}, E_{5}, E_{6}\right) \\
= & \text { (energy saving, low investment cost, reliability, } \\
& \text { easy to maintain, high life, low recovery cost). }
\end{aligned}
$$

Calculate the entropy weight using formulas (8) and (9) and get the weights of the indicators:
TABle 5: Economic feasible evaluation from experts.

\begin{tabular}{lccccc}
\hline Indicators & Expert 1 & Expert 2 & Expert 3 & Expert 4 & Expert 5 \\
\hline$E_{1}$ & 1 & 1 & 1 & 0.9 & 0.9 \\
$E_{2}$ & 0.9 & 0.9 & 0.8 & 0.9 & 0.9 \\
$E_{3}$ & 0.9 & 0.9 & 0.9 & 0.8 & 0.9 \\
$E_{4}$ & 0.8 & 0.8 & 0.8 & 0.9 & 0.8 \\
$E_{5}$ & 0.9 & 0.9 & 0.8 & 0.8 & 0.8 \\
$E_{6}$ & 0.8 & 0.9 & 0.8 & 0.8 & 0.8 \\
\hline
\end{tabular}

$W=(0.26,0.18,0.18,0.11,0.14,0.13)$.

The Euclidean distances of all the indicators from the ideal state and the negative ideal state are calculated based on formula (10):

$$
\begin{aligned}
& D_{j}^{*}=(0.1414,0.2828,0.2828,0.4123,0.3742,0.4123), \\
& D_{j}^{-}=(2.1494,1.9697,1.9697,1.8357,1.8814,1.8357) .
\end{aligned}
$$

According to formulas (11) and (12), the economic feasible degree of cloud rail is calculated:

$$
\lambda_{2}=\frac{\sum_{j=1}^{n} K_{j}^{*}}{\sum_{j=1}^{n}\left(K_{j}^{*}+K_{j}^{-}\right)}=\frac{1.9719}{2.2629}=0.87 .
$$

4.1.3. Step 3: Calculating the Environmental Improving Rate. Cloud rail is an innovative public traffic vehicle, which is introduced to reduce the pressure of urban traffic. At present, the most popular and environmental friendly public 
transport is metro. In order to evaluate the environmental improving rate, an environmental expert is invited to compare cloud rail with existing metro in environmental impacts. The $5 \times 5$ matrix is shown in Table 6 . The first number in every blank is the evaluation result of cloud rail, and the second one is the evaluation result of metro.

According to formula (13), the environmental improving rate is calculated:

$$
\lambda_{3}=\frac{S_{2}-S_{1}}{S_{i}-S_{1}}=0.89
$$

4.1.4. Step: 4 Calculating the Sustainability for Cloud Rail. The sustainability of cloud rail, represented by $\rho$, is calculated using formulas (14)-(17). According to Table 3, a conclusion can be drawn that cloud rail has a high level of sustainability:

$$
\rho=O T^{\prime}=O T \times \cos \theta=1.52449 \times \frac{2.31349}{3.04898}=1.17
$$

4.2. Results and Analysis. Based on the survey of social requirements for public traffic, we acquire ten social requirements. They are safe, fast, less traffic jam, low investment cost, short construction period, low pollution, low running noise, easy maintenance, saving land resources, and low recovery cost. Because of the haze weather, people' private cars can not be used normally. More people begin to go out by public transport. When choosing public transport, people gradually pay attention to the pollution of public transport to the environment. So, during the survey, it is found that low pollution has been a social requirement for public traffic. After building the matrix and calculating with the distance formula in the five-dimensional space, it is calculated that the social matching degree of cloud rail is 0.9. Based on experts' evaluation data, we calculate the weights of the economic indicators with the entropy weight method. According to the calculation result of TOPSIS, the economic feasible degree of cloud rail is 0.87 . Then, a comparison between cloud rail and metro is made to calculate the environmental improving rate of cloud rail. The calculation result is 0.89 . At last, the vector-cosine method is applied to calculate the final sustainability of cloud rail. According to the calculation results, it is found that the sustainability of cloud rail is 1.17 , which shows that cloud rail is of high level of sustainability.

\section{Conclusion}

The purpose of this study is to evaluate the sustainability for innovative products. The triple bottom line underlines that the sustainability included product's performance in social, economic, and environmental aspects. So, this study aims to evaluate product's sustainability in an integrated way. While considering the internal restrictive relationships among innovative product's economic, environmental, and social performances, the vector-cosine method has been used to evaluate the sustainability of innovative products.
TABLE 6: $5 \times 5$ matrix assessment for cloud rail and metro.

\begin{tabular}{lccccc}
\hline \multirow{2}{*}{ Life cycle } & \multicolumn{5}{c}{ Environmental impacts } \\
& Materials & $\begin{array}{c}\text { Energy } \\
\text { use }\end{array}$ & $\begin{array}{c}\text { Solid } \\
\text { residues }\end{array}$ & $\begin{array}{c}\text { Liquid } \\
\text { residues }\end{array}$ & $\begin{array}{c}\text { Gaseous } \\
\text { residues }\end{array}$ \\
\hline Preproduction & 4,1 & 3,2 & 4,2 & 4,2 & 4,2 \\
Production & 4,2 & 3,0 & 3,0 & 4,1 & 3,2 \\
Transportation & 4,1 & 3,1 & 3,1 & 4,1 & 3,1 \\
Usage & 4,1 & 4,2 & 4,1 & 4,2 & 4,1 \\
Disposal & 4,2 & 4,2 & 3,1 & 4,2 & 4,1 \\
\hline
\end{tabular}

5.1. Unique Contributions of the Paper. In order to evaluate the sustainability of an innovative product quantitatively in the three aspects, this paper proposes the concepts including social matching degree, economic feasible degree, and environmental improving rate to evaluate innovative product's performances in the three aspects. The fuzzy evaluation matrix and the distance formula in the five-dimensional space are combined to identify the social matching degree; the TOPSIS and the entropy weight method are integrated to calculate the economic feasible degree, and the simplified LCA is applied to estimate the environmental improving rate. Simply adding the value of social matching degree, economic feasible degree and environmental improving rate together cannot reflect the mutually restrictive relationships among them, so the vector-cosine method in the threedimensional space is proposed to calculate the final sustainability of innovative products, which regards innovative product as a vector in the three-dimensional space. The projection of the vector in the ideal direction is determined by calculating the cosine value of the deviating angle from the ideal direction and the size of the vector. The case study of the cloud rail, which is an innovative product made by $\mathrm{BYD}$, illustrates the validity of the evaluation process.

5.2. Theoretical and Managerial Implications. This study provides several theoretical contributions. First, it provides a series of quantitative calculation methods to evaluate the sustainability of innovative products. Most of the existing methods focus on how to achieve sustainability of products, but not on the evaluation of sustainability for innovative products that are being designed or have been designed. The quantitative methods are applied to calculate the concepts related with social, economic, and environmental aspects proposed in this paper. Because of the subjectivity and uncertainty existing in the data provided by experts, fuzzy theory and the entropy weight method are applied. Besides, the distance formula and the TOPSIS are also used to determine the social and economic performances of innovative products.

Second, this study combines two perspectives to evaluate the sustainability of innovative products: the perspective of triple bottom line and the perspective of life cycle assessment. From the perspective of triple bottom line, the performances of innovative products in social, economic, and environmental aspects are evaluated based on the values of social matching degree, economic feasible degree, and environmental improving rate which are calculated by 
quantitative methods. From the perspective of life cycle assessment, various forms of environmental impacts in product's whole life cycle have been calculated. Therefore, the evaluation process proposed in this paper can evaluate the sustainability of innovative products in a more comprehensive way.

Third, this study points out the mutually restrictive relationships among social, economic, and environmental performances for innovative products. Unilaterally, improving the performance in one aspect will inevitably lead to the lower performance in other two aspects. So, the evaluation of sustainability is not the simple addition of the performance in every aspect. In order to solve the problem, the vector-cosine method has been used to calculate the sustainability in an integrated way. The ideal direction in the three-dimensional space is regarded as the ideal balanced state of the three aspects. The projection of the vector in the ideal direction, which considers both the direction and the size of the vector, is regarded as the sustainability of innovative products.

This study also provides managerial contributions to the sustainable development both for enterprises and the society. With the continuous progress and development of modern society, changes are taking place in people's requirements for innovative products. Sustainable development is the main goal that people are pursuing at present. Products' sustainability is also a key consideration in choosing products for people. So, improving the sustainability of products has become an important aim in the innovation process for enterprises. The evaluation process of sustainability in this study will help enterprises to improve innovative product's social, economic, and environmental performances. Considering the cost and complex operation of LCA software, simplified LCA is applied by enterprises to make a comparison for innovative products and existing products. By evaluating the sustainability of innovative products, enterprises will have a deeper understanding for innovative products, which is conductive to the successful development of innovative products.

For the society, the evaluation of the sustainability of innovative products will further meet people's demands of sustainable development. Through the evaluation, the problems in the innovative products can be found. By solving the problems, the social satisfaction can be further improved. Besides, innovative products will have less impact on the environment. The society, economy, and environment will achieve the goal of sustainable development.

5.3. Limitations and Future Research. This study has its limitations. First, this study mainly provides quantitative methods for evaluating sustainability, while the sustainability indexes for different kinds of products should be further collected and analyzed. Second, since all the data for evaluating sustainability are obtain by experts, how to acquire valid data by big data for evaluating is a direction for further research. Third, this study takes the cloud rail as an innovative product for the case study, and more detailed case study for the common product should be done in future research.

\section{Data Availability}

The data used to support the findings of this study are available from the corresponding author upon request.

\section{Conflicts of Interest}

The authors declare that there are no conflicts of interest regarding the publication of this paper.

\section{Authors' Contributions}

Lisha Geng conceptualized the study. Zaojie Kong performed the formal analysis. Jinge Xing investigated the study. Haiyan Gao and Lisha Geng performed the methodology. Zaojie Kong, Lisha Geng, Jinge Xing, and Lixiao Geng supervised the study. Lisha Geng wrote the original draft. Haiyan Gao and Lisha Geng wrote the review and edited.

\section{Acknowledgments}

This research was funded by the Science technology Support Plan of Hebei Province (Grant Number: 16214533) http:// www.hebstd.gov.cn/.

\section{References}

[1] W. Reim, S. Lenka, J. Frishammar, and V. Parida, "Implementing sustainable product-service systems utilizing business model activities," Procedia CIRP, vol. 64, pp. 61-66, 2017.

[2] T. Dyllick and Z. Rost, "Towards true product sustainability," Journal of Cleaner Production, vol. 162, pp. 346-360, 2017.

[3] U. Nations, "Agenda 21: programme of action for sustainable development," in Proceedings of the United Nations Conference on Environment and Development, Rio de Janeiro, Brazil, June 1992.

[4] J. Elkington, Cannibals with Forks: The Triple Bottom Line of 21st Century Business, New Society Publisher, Gabriola Island, BC, Canada, 1997.

[5] A. Hosseinpour, Integration of Axiomatic Design with Quality Function Deployment for Sustainable Modular Product Design, University of Manitoba, Manitoba, Canada, 2014.

[6] J. A. Erkoyuncu, R. Roy, E. Shehab, C. Durugbo, S. Khan, and P. Datta, "An effective uncertainty based framework for sustainable industrial product-service system transformation," Journal of Cleaner Production, vol. 208, pp. 160-177, 2019.

[7] M. Held, D. Weidmann, D. Kammerl et al., "Current challenges for sustainable product development in the German automotive sector: a survey based status assessment," Journal of Cleaner Production, vol. 195, pp. 869-889, 2018.

[8] L. M. Edinger-Schons, J. Sipilä, S. Sen, G. Mende, and J. Wieseke, "Are two reasons better than one? The role of appeal type in consumer responses to sustainable products," Journal of Consumer Psychology, vol. 28, no. 4, pp. 644-664, 2018.

[9] S. Ahmad, K. Y. Wong, M. L. Tseng, and W. P. Wong, "Sustainable product design and development: a review of tools, applications and research prospects," Resources, Conservation and Recycling, vol. 132, pp. 49-61, 2018.

[10] J. Cerri, F. Testa, and F. Rizzi, "The more i care, the less i will listen to you: how information, environmental concern and ethical production influence consumers' attitudes and the 
purchasing of sustainable products," Journal of Cleaner Production, vol. 175, pp. 343-353, 2018.

[11] M. Cordella and C. Hidalgo, "Analysis of key environmental areas in the design and labelling of furniture products: application of a screening approach based on a literature review of LCA studies," Sustainable Production and Consumption, vol. 8 , pp. 64-77, 2016.

[12] C. Favi, M. Marconi, M. Germani, and M. Mandolini, "A design for disassembly tool oriented to mechatronic product de-manufacturing and recycling," Advanced Engineering Informatics, vol. 39, pp. 62-79, 2019.

[13] G. M. Kane, C. A. Bakker, and A. R. Balkenende, "Towards design strategies for circular medical products," Resources, Conservation and Recycling, vol. 135, pp. 38-47, 2018.

[14] M. Ameli, S. Mansour, and A. Ahmadi-Javid, "A simulationoptimization model for sustainable product design and efficient end-of-life management based on individual producer responsibility," Resources, Conservation and Recycling, vol. 140, pp. 246-258, 2019.

[15] A. Z. M. Noor, M. H. F. M. Fauadi, F. A. Jafar, and N. R. Mohamad, "New proposed methodology for decision making purpose in design for remanufacturing," Advanced Science Letters, vol. 24, no. 10, pp. 7539-7544, 2018.

[16] C. Thies, K. Kieckhäfer, T. S. Spengler, and M. S. Sodhi, "Operations research for sustainability assessment of products: a review," European Journal of Operational Research, vol. 274, no. 1, pp. 1-21, 2019.

[17] E. Grubert, "The need for a preference-based multicriteria prioritization framework in life cycle sustainability assessment," Journal of Industrial Ecology, vol. 21, no. 6, pp. 1522-1535, 2017.

[18] V. Campos-Guzmán, M. S. García-Cáscales, N. Espinosa, and A. Urbina, "Life cycle analysis with multi-criteria decision making: a review of approaches for the sustainability evaluation of renewable energy technologies," Renewable and Sustainable Energy Reviews, vol. 104, pp. 343-366, 2019.

[19] G. Lisha, K. Zaojie, and G. Lixiao, "A creative study on the method of determining the importance of customer requirements in QFD," Contemporary Economic Management, vol. 38, pp. 20-25, 2016.

[20] D. L. Mon, C. H. Cheng, and J. C. Lin, "Evaluating weapon system using fuzzy analytic hierarchy process based on entropy weight," Fuzzy Sets and Systems, vol. 62, no. 2, pp. 127-134, 1994.

[21] X. Li, K. Wang, L. Liu, J. Xin, H. Yang, and C. Gao, “Application of the entropy weight and TOPSIS method in safety evaluation of coal mines," Procedia Engineering, vol. 26, pp. 2085-2091, 2011.

[22] E. O. Agyekum, K. P. J. Fortuin, and E. van der Harst, "Environmental and social life cycle assessment of bamboo bicycle frames made in Ghana," Journal of Cleaner Production, vol. 143, pp. 1069-1080, 2017.

[23] C. J. Yang and J. L. Chen, "Forecasting the design of ecoproducts by integrating TRIZ evolution patterns with CBR and Simple LCA methods," Expert Systems with Applications, vol. 39, no. 3, pp. 2884-2892, 2012.

[24] T. E. Graedel, B. R. Allenby, and P. R. Comric, "Matrix approaches to abridged life cycle assessment," Environmental Science \& Technology, vol. 29, no. 3, pp. 134A-139A, 1995.

[25] https://baike.baidu.com/pic/\%E4\%BA\%91\%E8\%BD\%A8/ 20140693/21408743/d6ca7bcb0a46f21ff1fb87ceff246b600d33ae64? $\mathrm{fr}=$ lemma\&ct $=$ cover\#aid $=21408743 \&$ pic $=$ d6ca7bcb0a $46 f 21 \mathrm{ff} 1 \mathrm{fb} 8$ 7ceff246b600d33ae64. 


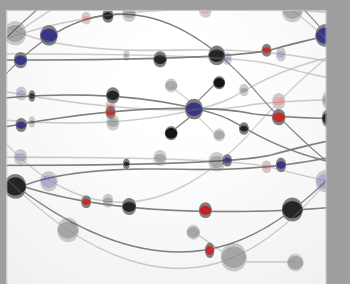

The Scientific World Journal
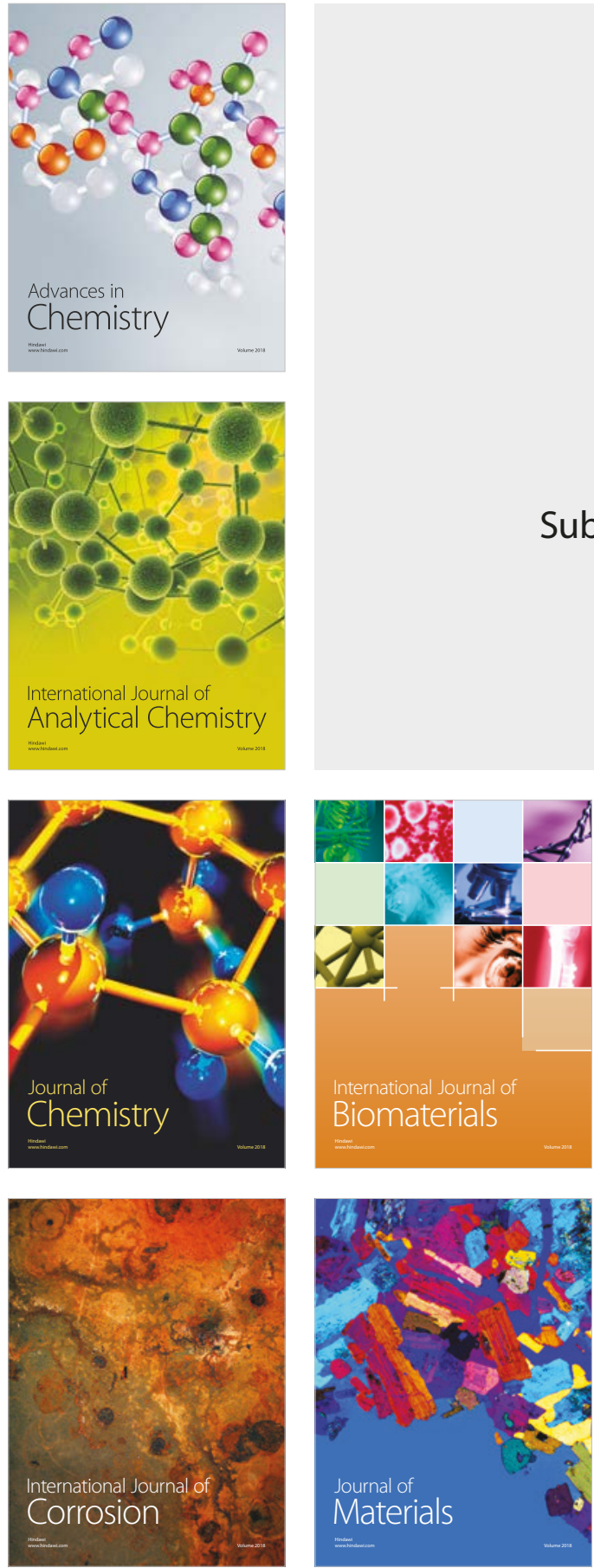

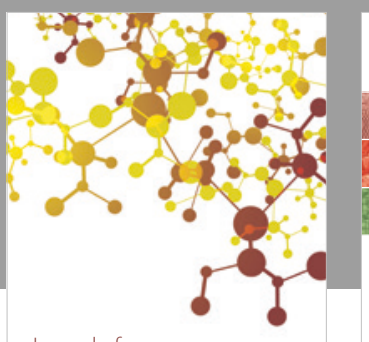

Journal of

Applied Chemistry
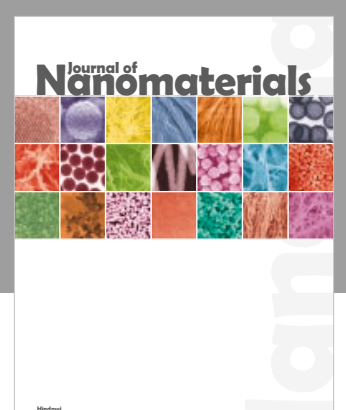

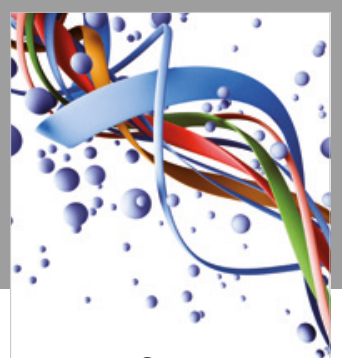

Scientifica

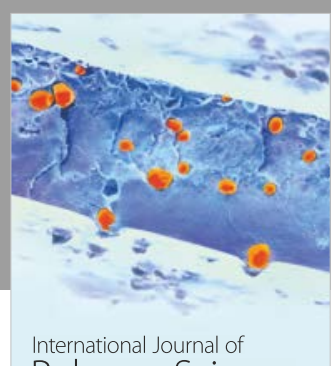

Polymer Science

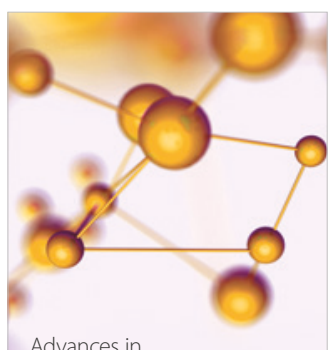

Physical Chemistry
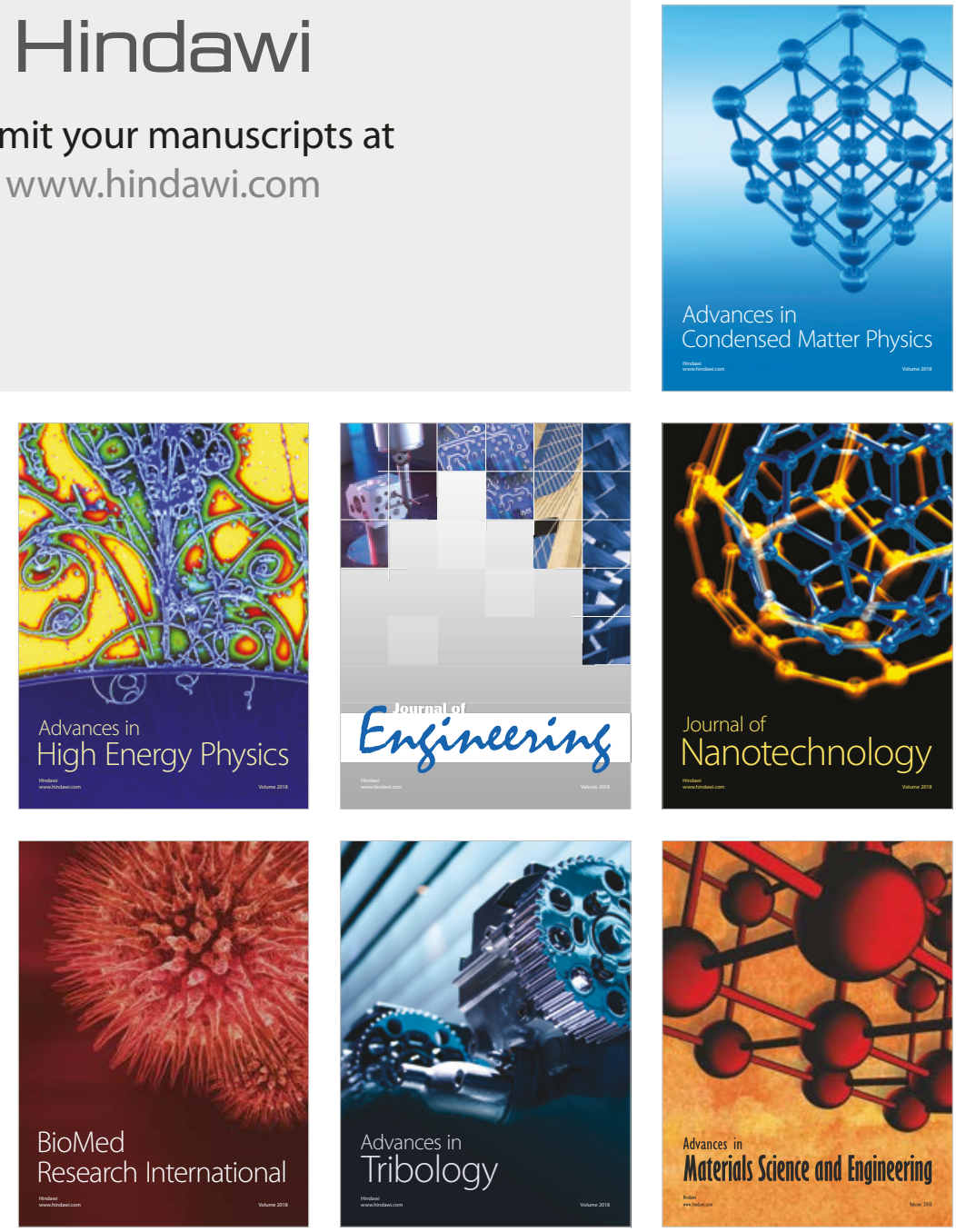